\title{
(1)
}

UNIVERSIDAD PERUANA DE CIENCIAS APLICADAS

FACULTAD DE NEGOCIOS

PROGRAMA ACADÉMICO DE ADMINISTRACIÓN DE EMPRESAS

\section{LIMA: ESCENARIO POTENCIAL PARA UN MANEJO DE RAEE EFICIENTE}

\author{
TESIS \\ para optar el grado de Licenciado en Administración de Empresas
}

AUTORES

Gavelán Villanueva, María (0000-0003-4807-7683)

Granda Santana, Rodrigo (0000-0002-6868-9292)

ASESOR

Zilberman Fleischman, Jack (0000-0003-0956-4059)

Lima, 19 de Julio de 2018 
"Una sociedad se define no solo por lo que crea sino por lo que se niega a destruir" John C. Sawhill 
Agradecimientos

A los profesionales del ambiente que creyeron en nuestro proyecto 


\section{RESUMEN}

La tecnología, sin duda, ha aportado rapidez y eficiencia a las labores diarias del ser humano. Sin embargo, la constante mejora de estos aparatos eléctricos y electrónicos se convierte en basura electrónica o RAEE cuando llegan al final de su vida útil. Aunque la preocupación por este problema nace en Europa, nuestro país ya cuenta con un reglamento para la gestión de RAEE. La investigación cualitativa que hemos desarrollado está enfocada a Lima Metropolitana y nos ha permitido conocer cómo funciona el sistema, los actores que intervienen y cómo sus acciones influyen directamente en los resultados que se esperan, las políticas de Estado y las consecuencias que una mala gestión de RAEE puede causar a nuestra salud y a nuestro entorno. Asimismo, hemos tratado de identificar oportunidades de mejora y marcar un precedente para que futuros tesistas continúen desarrollando y aportando a este tema que desde su elección marcó para nosotros un antes y un después.

Palabras clave :gestión de residuos electrónicos ; RAEE ; reciclaje electrónico 


\begin{abstract}
Technology, without a doubt, has brought speed and efficiency to the daily tasks of humans. Nevertheless, the constant improvement of these electrical and electronic devices becomes electronic waste or WEEE when they reach the end of their useful life. Although the concern for this problem arises in Europe, our country has already a regulation for the WEEE management. The qualitative research we have developed is focused on Metropolitan Lima and has allowed us to know how the system works, the stakeholders involved and how their actions directly influence the expected results, State policies and the consequences that poor management of WEEE can affect our health and our environment. Likewise, we have tried to identify opportunities for improvement and set a precedent for future thesis students to continue developing and contributing to this topic that, from their election, marked for us a before and after.
\end{abstract}

Keywords : electronic waste management; WEEE; electronic recycling 


\section{TABLA DE CONTENIDO}

RESUMEN

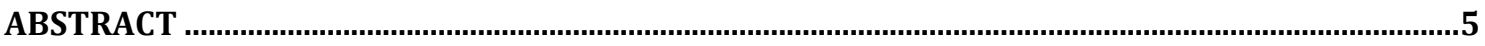

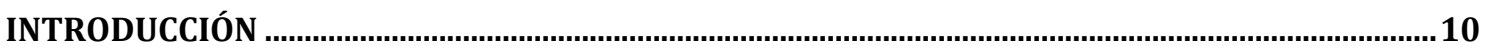

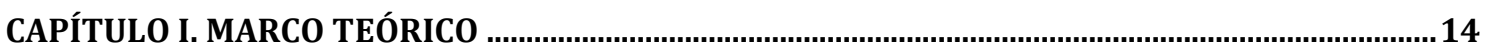

1.1 RECICLAJE DE RAEE ............................................................................................................................

1.1.1 Definición de RAEE y características............................................................................................ 14

1.1.2 Clasificación de los RAEE .........................................................................................................

1.1.3 Consecuencias para la salud y el medio ambiente ......................................................................... 15

1.1.4 Antecedentes del manejo de RAEE ..............................................................................................17

1.1.5 Estadísticas de RAEE a nivel mundial ......................................................................................

1.1.6 Realidad en la política de gestión de RAEE en los principales países de la región.................... 19

1.2 GESTION DE RAEE EN Lima MetropolitanA................................................................................................ 19

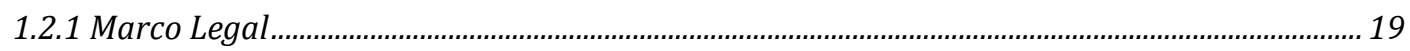

1.2.2 Situación actual de la gestión de RAEE en Lima..........................................................................20

1.2.3 Actores en la gestión de RAEE en Lima Metropolitana .................................................................... 21

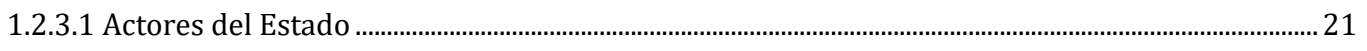

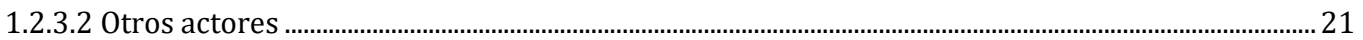

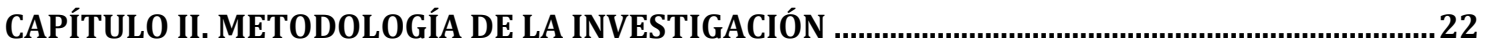

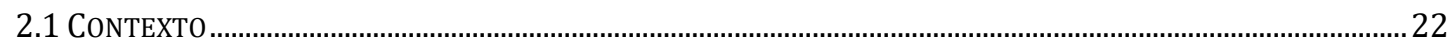

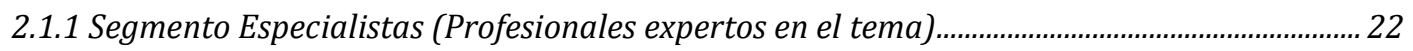

2.1.2 Segmento Sector Privado y Estatal (Responsables de áreas relacionadas al tema) .............. 22

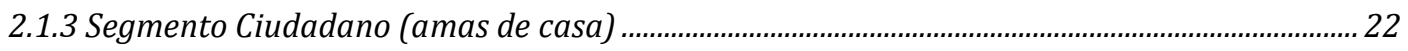

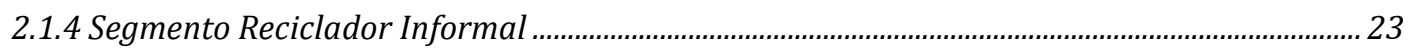

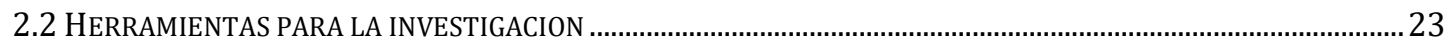

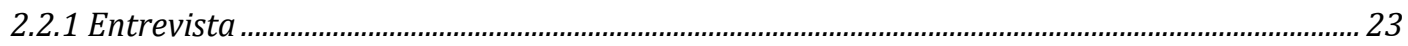

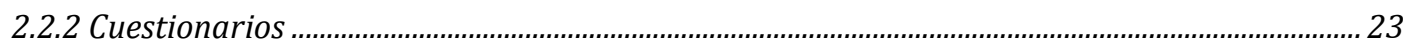

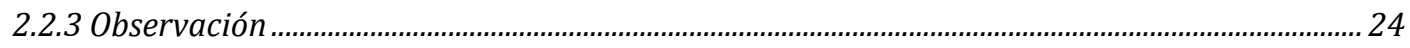

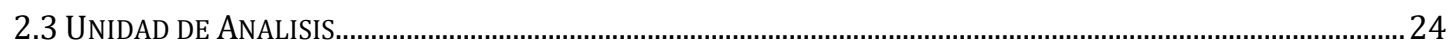

2.3.1 Segmento Especialistas (Profesionales expertos en el tema).

2.3.2 Segmento Sector Privado y Estatal (Responsables de áreas relacionadas al tema) ............... 24

2.3.3 Segmento Ciudadano (Amas de casa de seis distritos de la capital)..........................................25

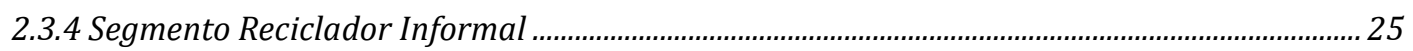

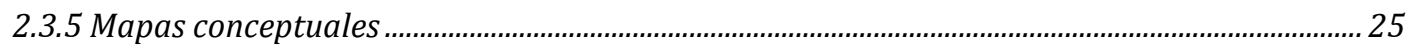




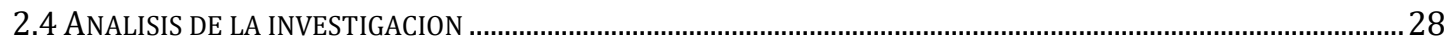

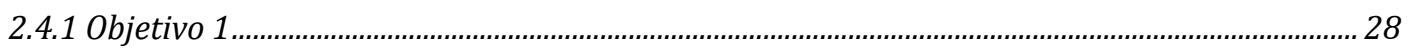

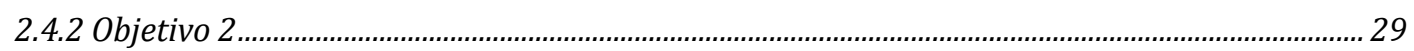

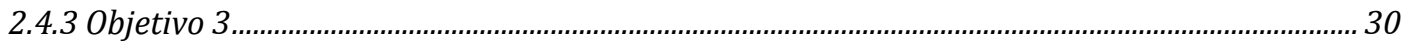

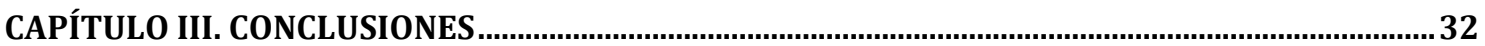

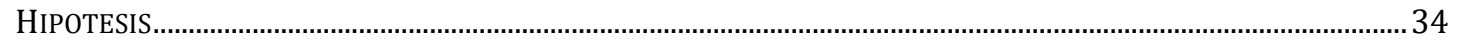

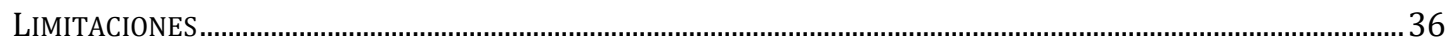

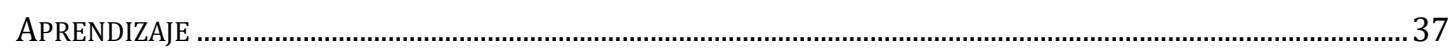

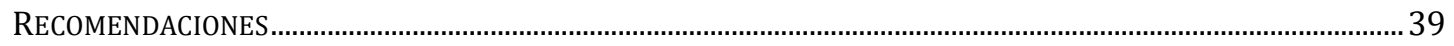

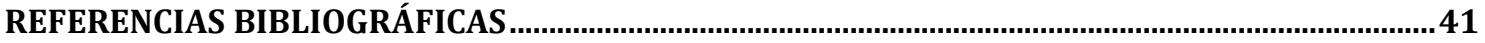

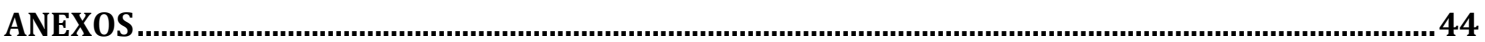




\section{ÍNDICE DE TABLAS}

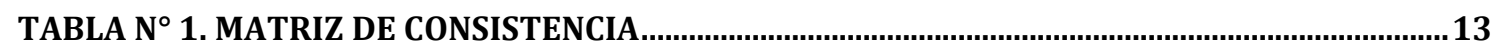

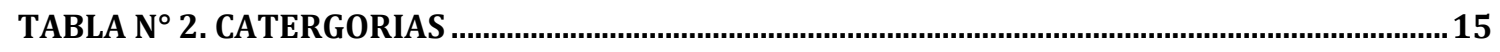

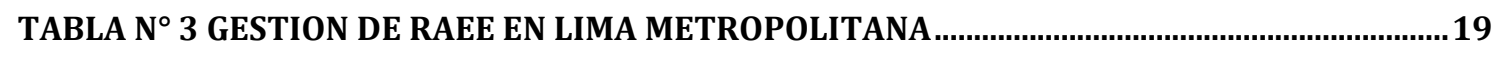

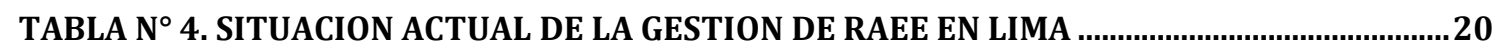




\section{ÍNDICE DE FIGURAS}

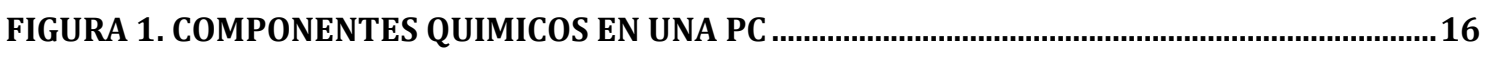

FIGURA 2. SUSTANCIAS QUIMICAS NOSCIVAS PARA EL SER HUMANO ........................................16

FIGURA 3. GENERACION DE RAEE EN EL MUNDO 2010 - 2016 ....................................................

FIGURA 4. MANEJO DE RESIDUOS SOLIDOS EN LIMA METROPOLITANA: ESCENARIO ACTUAL

FIGURA 5. MAPA CONCEPTUAL 1: ACTORES QUE INTERVIENEN EN LA GESTION DE RAEE EN

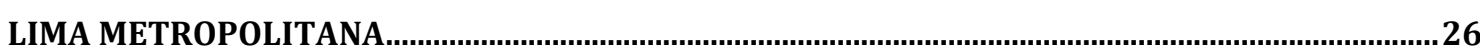

FIGURA 6. MAPA CONCEPTUAL 2: POLITICAS DEL ESTADO PARA LA GESTION DE RAEE EN

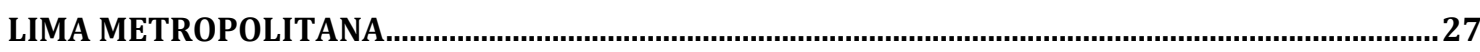

FIGURA 7. MAPA CONCEPTUAL 3: IMPACTO NEGATIVO POR UNA MALA GESTION DE RAEE EN

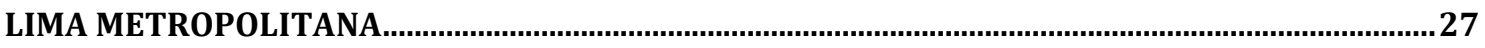




\section{INTRODUCCIÓN}

Desde la creación del Ministerio del Ambiente el 14 de mayo de 2008, nuestro país ha dejado en evidencia un interés comprensible por el cuidado del medio ambiente. Pero medioambiente no solo es hablar de basura orgánica, plásticos o papeles, también es hablar de tecnología. El mundo de hoy tiene un aliado irremplazable que le facilita la vida debido a las múltiples funciones que realiza. Los 1lamados "artefactos eléctricos electrónicos" trabajan con ayuda de la energía eléctrica y están compuestos por diferentes sustancias químicas que conviven a diario con nosotros y que al final de su vida útil se convierten en basura electrónica.

Nuestra investigación tiene la intención de mostrar cómo se realiza el manejo y gestión del reciclaje electrónico en Lima Metropolitana considerando el rol que desempeña cada uno de sus actores.

Diferentes medios de comunicación han ayudado a fomentar la constante preocupación que existe por el mal trato que se le da al medio ambiente y desde siempre hemos sabido que la basura se arroja en un tacho o pero ¿acaso de 40 pulgadas cabe en un tacho de tamaño promedio? ¿Puedo arrojar mi computadora malograda a un tacho de basura? Ante estas interrogantes la salida más rápida sería llevar ambos productos a un taller cercano y no recogerlos nunca, aun cuando no sepamos qué hará después el técnico con los artefactos.

En la actualidad el Estado peruano, a través del Ministerio del Ambiente, viene ejecutando el Plan Nacional de Acción Ambiental que involucra a todos los actores que de acuerdo al Reglamento Nacional para la Gestión y Manejo de los residuos de aparatos eléctricos y electrónicos deben cumplir con funciones específicas con el objetivo de lograr un control con respecto a los desperdicios que generamos a diario. El daño silencioso que la contaminación electrónica produce tiene a muchos países del mundo trabajando en iniciativas innovadoras para lograr un equilibrio en la relación hombre-tecnología. Este trabajo ha permitido el y e para aquellos países que deseen sumarse a esta carrera contra la indiferencia de las personas. 
A pesar de que el Estado peruano viene trabajando en este tema desde el año 2012, la población no está del todo informada y no conoce que existen centros de acopio para la basura electrónica que produce ni mucho menos conoce los daños que esta basura puede causarle a su salud y que más del $80 \%$ de ella puede ser reciclada. Mientras esta situación no cambie la acumulación se convertirá en un problema difícil de combatir y las escenas del film animado de ciencia ficción del año 2008 llamado WALL-E ya no serán tan ajenas a nuestra realidad.

Durante la investigación identificamos que el reglamento vigente considera sanciones e incentivos para los generadores, productores y operadores en caso incumplan o no las condiciones establecidas por ley y que desarrollaremos en nuestro marco teórico.

Ante lo expuesto surge la pregunta que es el objeto de nuestro problema: ¿por qué no se ha logrado una sostenibilidad en el manejo de los artefactos eléctricos y electrónicos en Lima Metropolitana con ayuda de los actores que intervienen en el sistema?

La hipótesis a partir de la cual se desarrolla nuestra investigación plantea que la falta de una cultura de reciclaje electrónico entre los actores que intervienen en el manejo de estos residuos pone en riesgo la sostenibilidad del sistema en Lima Metropolitana.

El objetivo general de esta investigación es comprender cómo se desarrolla el sistema de reciclaje de residuos electrónicos en Lima Metropolitana actualmente y qué actores contribuyen a la sostenibilidad del sistema.

Entre los objetivos específicos, se encuentran los siguientes.

1. Analizar las iniciativas y avances en el sistema de reciclaje electrónico por parte de los actores del sistema

2. Evaluar los incentivos que ofrece el Estado peruano y el nivel de satisfacción por parte de los beneficiados

3. Identificar las políticas de fiscalización del estado y si existen sanciones efectivas

4. Evaluar las consecuencias de la falta de reciclaje electrónico

En tal sentido, la percepción de que no se ha avanzado en este tema, justifica nuestro interés por desarrollar una investigación que amplíe el panorama de aquellos que al igual que nosotros (en un primer momento) desconocíamos acerca de este problema que al día 
de hoy proyecta un crecimiento del 5\% de basura electrónica para el 2025 con una cifra alarmante de 54 millones de toneladas (ver Anexo 1).

A partir de esta investigación buscamos evaluar también el papel que desarrollan los actores que participan en el sistema, piezas fundamentales para lograr un equilibrio en el manejo de residuos electrónicos y que contribuirá a mitigar el impacto negativo en nuestra ciudad.

Es evidente que nuestro estudio será descriptivo y que ello facilitara el análisis de nuestra realidad sin dejar de considerar las experiencias recogidas por los países vecinos de esta parte del continente.

A continuación adjuntamos la Matriz de Consistencia de nuestra investigación, la cual permite evaluar el grado de coherencia y conexión lógica entre el título, el problema, los objetivos, la hipótesis, las variables, el tipo, el método, diseño de investigación y la muestra de estudio. 


\begin{tabular}{|c|c|c|c|c|}
\hline PROBLEMAS & OBJETIVOS & HIPÓTESIS/PROBLEMA & VARIABLES & METODOLOGÍA \\
\hline $\begin{array}{l}\text { Problema principal } \\
\text { ¿Por qué no se ha logrado una } \\
\text { sostenibilidad en el manejo del } \\
\text { RAEE en Lima Metropolitana con } \\
\text { ayuda de los actores que } \\
\text { intervienen en el sistema? } \\
\text { Problemas secundarios } \\
\text { 1. Exigencias por parte de las } \\
\text { autoridades que hacen poco } \\
\text { flexible el acceso al sistema y } \\
\text { se convierten en una barrera } \\
\text { 2. Falta de incentivos por parte } \\
\text { del Estado } \\
\text { 3. Falta de control o } \\
\text { fiscalización con sanciones } \\
\text { ejemplares } \\
\text { 4. Daño irreversible al medio } \\
\text { ambiente y a la salud de las } \\
\text { personas }\end{array}$ & $\begin{array}{l}\text { Objetivo general } \\
\text { Conocer cómo se desarrolla el sistema } \\
\text { de reciclaje de RAEE Lima } \\
\text { Metropolitana en la actualidad y qué } \\
\text { actores contribuyen a la sostenibilidad } \\
\text { del sistema. } \\
\text { Objetivos específicos } \\
\text { 1. Analizar las iniciativas y avances } \\
\text { en el sistema de reciclaje } \\
\text { electrónico por parte de los actores } \\
\text { del sistema } \\
\text { 2. Evaluar los incentivos que ofrece el } \\
\text { estado y el nivel de satisfacción por } \\
\text { parte de los beneficiados } \\
\text { 3. Identificar las políticas de } \\
\text { fiscalización del Estado y si existen } \\
\text { sanciones efectivas } \\
\text { Evaluar las consecuencias de la } \\
\text { falta de reciclaje electrónico }\end{array}$ & $\begin{array}{l}\text { Hipótesis general } \\
\text { La falta de una cultura de reciclaje } \\
\text { entre los actores que intervienen } \\
\text { en el manejo de un RAEE eficiente } \\
\text { pone en riesgo la sostenibilidad del } \\
\text { sistema. }\end{array}$ & $\begin{array}{ll}\text { - } & \text { Actores } \\
- & \text { Políticas } \\
- & \text { Incentivos } \\
- & \text { Sanciones } \\
- & \text { Impacto negativo }\end{array}$ & $\begin{array}{l}\text { Tipo de investigación: } \\
\text { Cualitativa Descriptiva } \\
\text { Método del caso } \\
\text { Muestra } \\
\text { No representativa a través de } \\
\text { entrevistas semiestructuradas } \\
\text { - Especialistas } \\
\text { - Mandos altos privados } \\
\text { - Mandos altos estatales } \\
\text { - Ciudadano } \\
\text { - Reciclador informal } \\
\text { Técnica de triangulación para } \\
\text { darle sustento y validez a la } \\
\text { investigación cualitativa }\end{array}$ \\
\hline
\end{tabular}




\section{CAPÍTULO I. MARCO TEÓRICO}

\subsection{Reciclaje de RAEE}

\subsubsection{Definición de RAEE y características}

La basura electrónica es uno de los grandes problemas ecológicos de los últimos años en nuestro planeta. (Gestión de residuos electrónicos en América Latina, 2009, p. 26).

Con el desarrollo de la tecnología, los consumidores se vuelven más demandantes. Asimismo, la titánica competencia de las marcas por brindar los últimos avances tecnológicos hace que desarrollen aparatos cada vez más económicos que no permiten una reparación, lo cual, genera una aceleración en el tiempo de vida útil de cada uno de estos objetos. Esto genera un incremento en la tasa de basura electrónica a nivel mundial.

Es por ello que el objetivo de la investigación es conocer cómo se desarrolla el sistema de reciclaje de residuos electrónicos en Lima Metropolitana actualmente y qué actores contribuyen a la sostenibilidad del sistema.

Debemos encontrar las formas más eficientes de implementar un sistema RAEE. Es preciso detallar las necesidades que llevaron a países del mundo a implementar un método eficiente, capaz de disminuir el incremento de la basura electrónica, obteniendo la mayor reutilización de los elementos que la componen. En esta investigación, conoceremos las categorías, países, actores involucrados y plan de manejo de los RAEE en esta gran iniciativa ambiental.

\subsubsection{Clasificación de los RAEE}

Debido a la diversidad de productos eléctricos y electrónicos, los RAEE se clasifican en 10 categorías que permiten entender y generar acciones específicas sobre los productos que se encuentran en cada una de ellas. 
Tabla $\mathrm{N}^{\circ}$ 2. Catergorías

\begin{tabular}{|l|l|}
\hline $\mathrm{N}^{\mathbf{0}}$ & Categoría \\
\hline 1 & Grandes electrodomésticos \\
\hline 2 & Pequeños electrodomésticos \\
\hline 3 & Equipos de informática y telecomunicaciones \\
\hline 4 & Aparatos eléctricos de consumo \\
\hline 5 & Aparatos de alumbrado \\
\hline 6 & $\begin{array}{l}\text { Herramientas eléctricas y electrónicas (con excepción de las herramientas } \\
\text { industriales fijas de gran envergadura) }\end{array}$ \\
\hline 7 & Juguetes o equipos deportivos y de tiempo libre \\
\hline 8 & $\begin{array}{l}\text { Aparatos médicos (con excepción de todos los productos implantados o } \\
\text { infectados) }\end{array}$ \\
\hline 9 & Instrumentos de vigilancia y control \\
\hline 10 & Máquinas expendedoras \\
\hline
\end{tabular}

\subsubsection{Consecuencias para la salud y el medio ambiente $\underline{1.1 .}$}

\section{Consecuencias para la salud y el medio ambiente}

La mayoría de personas compramos tecnología sin preocuparnos por el fin de la vida útil y gestión del reciclaje de cada aparato. Existiendo reglamentaciones vigentes en una gran cantidad de países del mundo que conoceremos en esta investigación, aún existen países que no regulan la gestión de los RAEE. Estos, al no tener un tratamiento adecuado y que son mezclados con basura común en los vertederos, generan problemas ambientales, ya que son incinerados sin la clasificación previa. Al no tener control alguno, las incidencias pueden generar impactos negativos para la salud y el medio ambiente.

Según García Fernández, B. y Boquete, T. (2016, p. 45) en su libro Basura Electrónica: Un Mundo Dividido mencionan que es común que este tipo de basureros se encuentren al aire libre favoreciendo la diseminación y exposición de las sustancias químicas del AEE a los cambios climático, convirtiéndose en una fuente importante de enfermedades transmitidas por diferentes vectores.

Los RAEE contienen elementos importantes para la extracción y muchos de ellos son peligrosos para la salud. Al estar expuestos a los diferentes cambios climáticos 
contaminan el aire, la tierra y el agua. Estas sustancias son ingeridas de diferentes formas por las especies que forman parte de la cadena alimenticia, quienes posteriormente desarrollarán enfermedades afectando la calidad de vida de quienes los ecosistemas. (García, 2016).

Sin duda, una mala gestión de los RAEE involucra un gran daño para el medio ambiente, personas y ecosistemas, afectando su flora y fauna. Los más afectados son las personas de escasos recursos que muchas veces viven cerca de estos vertederos y son expuestos directamente a estos elementos. Actualmente en Acrra, Ghana, ciertos metales presentaban concentraciones que superaban cien veces los niveles normales en suelos, como por ejemplo el plomo, que es altamente tóxico. También se detectó contaminación por otros metales tóxicos, como el cadmio y el antimonio (ver Figuras 1 y 2).

Figura 1. Componentes químicos en una PC

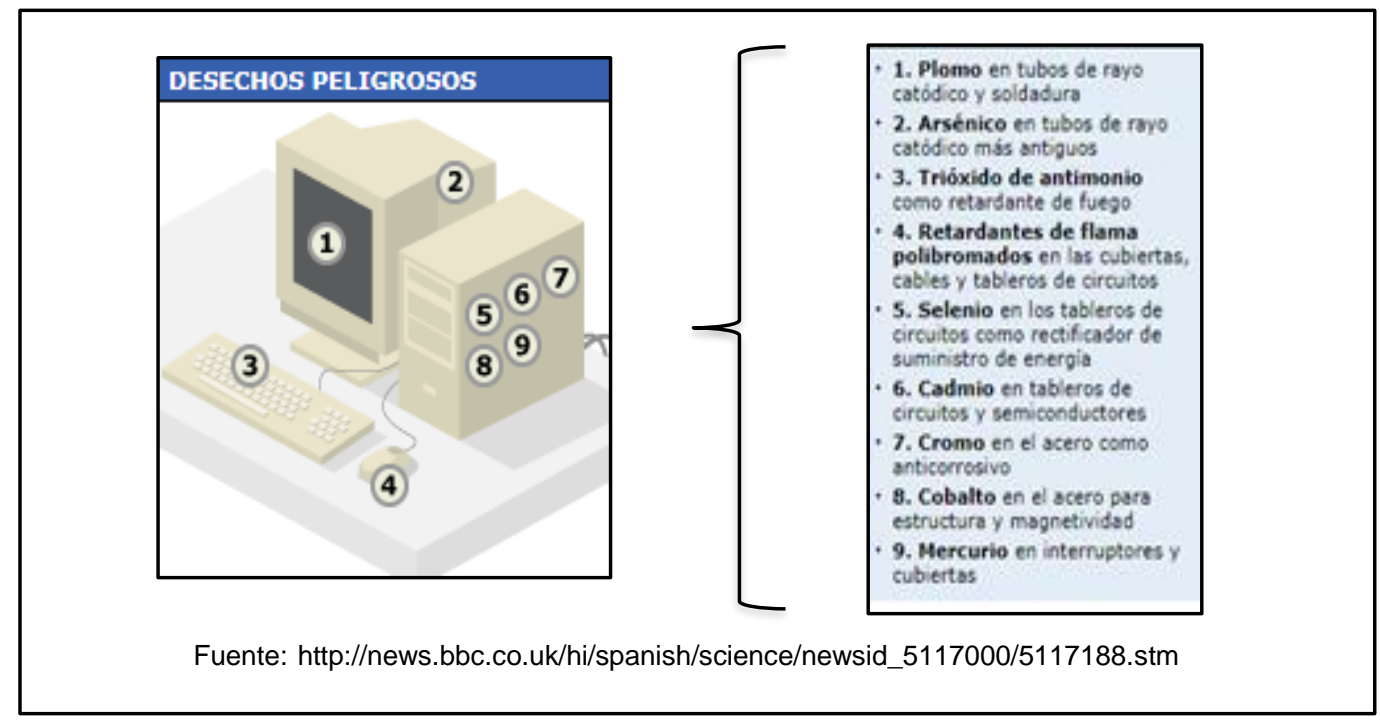

Figura 2. Sustancias químicas noscivas para el ser humano

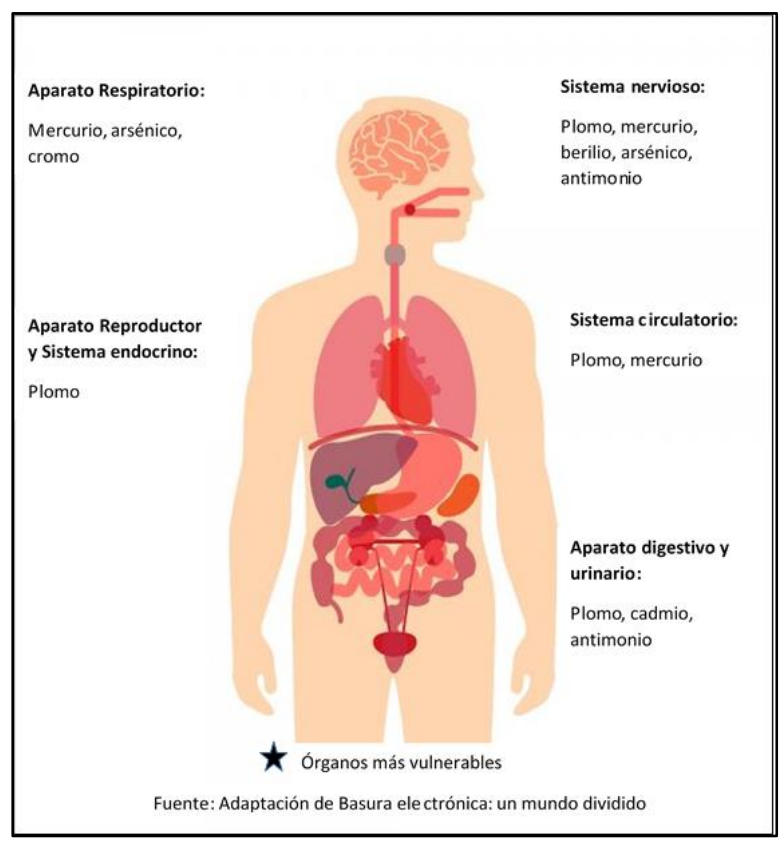




\subsubsection{Antecedentes del manejo de RAEE}

A inicios de los noventa, el economista Larry Summers hablaba del sentido económico de exportar desechos del primer mundo a países en desarrollo para que estos puedan beneficiarse (Gestión de residuos electrónicos en América Latina, 2009).

Los puntos más importantes de su iniciativa eran los siguientes:

- Los países con salarios más bajos perderían la menor cantidad de productividad por "mayor morbilidad y mortalidad", dado que el costo que habría que recuperar sería mínimo.

- Los países menos desarrollados, específicamente los de África, estaban no contaminados en grados importantes y, por lo tanto podrían obtener beneficios de los planes mercantiles.

- La protección ambiental por "razones estéticas y de salud" es esencialmente un lujo de los ricos, considerando que la mortalidad es un problema de tal magnitud en estos países en desarrollo, que los efectos relativamente mínimos de una mayor contaminación empalidecerían en comparación con los problemas que esas áreas ya enfrentan.

Sin embargo, esto no reduciría la basura, simplemente la trasladaría a países menos desarrollados que quizás no tendrían los medios para subsanar el incremento de la importación de basura electrónica de los países desarrollados.

Es por esto que en 1992 entra en vigor la iniciativa internacional del convenio de Basilea sobre el Control de los Movimientos Transfronterizos de Desechos Peligrosos y su Eliminación.

Dentro de los puntos más importantes de este convenio se menciona lo siguiente:

- El tránsito transfronterizo de desechos peligrosos debe ser reducido al mínimo consistente con su manejo ambientalmente apropiado.

- Los desechos peligrosos deben ser tratados y dispuestos lo más cerca posible de la fuente de su generación.

- Los desechos peligrosos deben ser reducidos y minimizados en su fuente. 


\subsubsection{Estadísticas de RAEE a nivel mundial}

En 1994, se estimaba unos 7 millones de toneladas en computadoras obsoletas a nivel mundial. Con el paso de los años y la evolución constante de la tecnología, estos indicadores se han incrementado.

En un artículo publicado por Farbiarz (2008) en el portal web responsable de comunicación en derecho ambiental, se menciona que en el 2016, el mundo generó 44.7 millones de toneladas métricas (Mt) de RAEE, lo que representa un equivalente a $6,1 \mathrm{~kg}$ por persona. Esto significa que esta tendencia permanecerá durante los próximos años.

Es importante saber que a la fecha, se estima que solo el $20 \%$ de residuos lleva un tratamiento de reciclaje adecuado. La diferencia termina en vertederos ilegales.

En el siguiente cuadro se muestra la tendencia al alza en la generación de RAEE por persona, desde el 2010, que se ha incrementado en 35\%. Esto es un dato general. Sin embargo, si lo vemos por continentes o países de la región o los países más industrializados, los resultados pueden ser aún mayores (ver Figura 3).

Figura 3. Generación de RAEE en el mundo 2010 - 2016

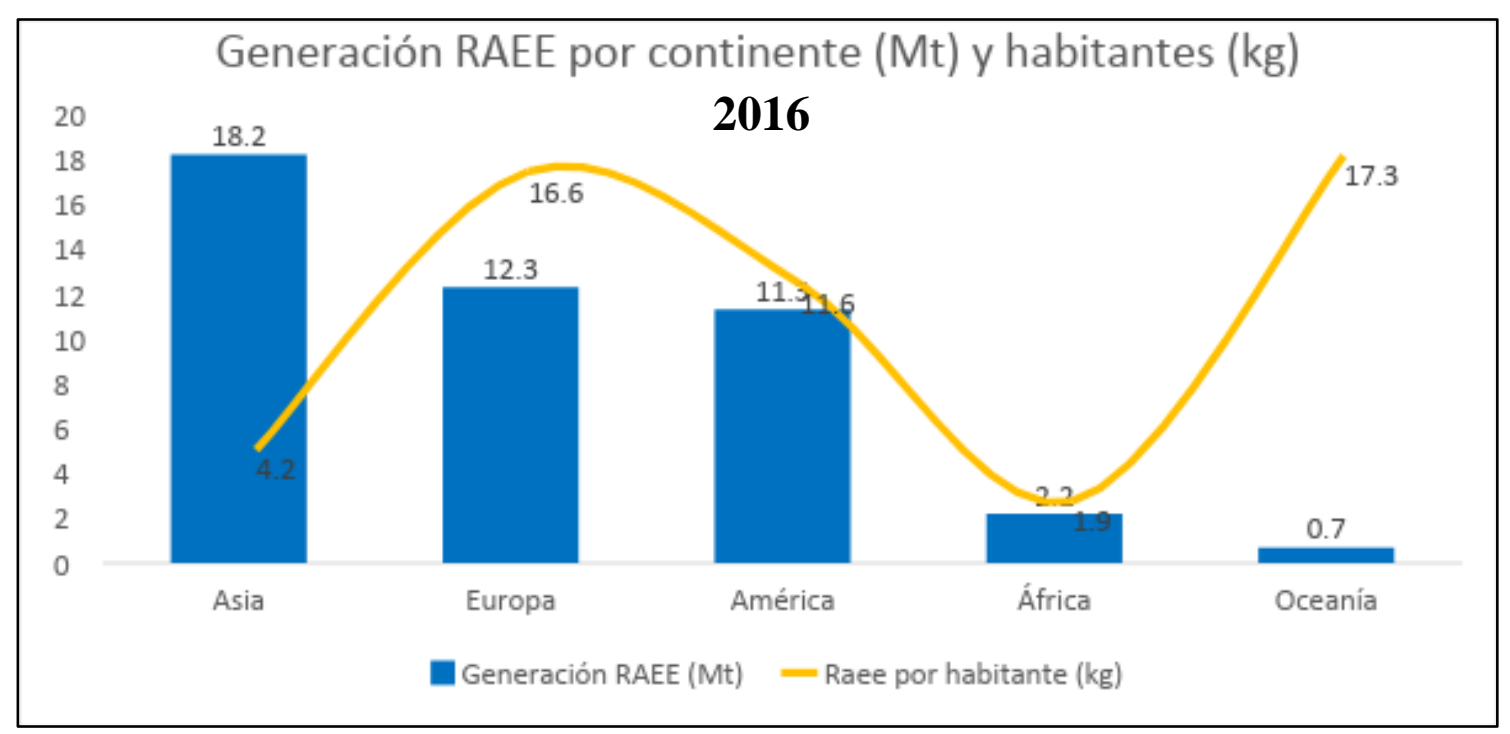

Fuente: Elaboración propia con datos de https://www.residuosprofesional.com/informe-tendencias-raee-nivel-mundial/ 


\subsubsection{Realidad en la política de gestión de RAEE en los principales países de la región}

La creación de un ministerio dedicado al ambiente forma parte de la preocupación de los países por conservar un medio ambiente saludable. Por ello, como parte de nuestra investigación, hemos considerado importante hacer un breve análisis de 3 de los principales países de la región con respecto a nuestro caso de estudio para saber cuánto han avanzado en manejo de RAEE.

Un común denominador entre los países que incluyen el manejo de RAEE como parte de su política de Estado es que trabajan en base a la metodología de "Responsabilidad extendida del productor" que consiste en que el productor debe hacerse cargo del artefacto que comercializa aun cuando la venta ya se haya efectuado.

\subsection{Gestión de RAEE en Lima Metropolitana}

Tabla N 3 Gestión de RAEE en Lima Metropolitana

\begin{tabular}{|l|c|c|c|}
\hline \multicolumn{1}{|c|}{ Datos } & Argentina & Colombia & Chile \\
\hline Población (millones) & 43000000 & 48750000 & 17000000 \\
\hline Superficie $\mathrm{Km}^{2}$ & 2780400 & 1141749 & 756102 \\
\hline RAEE Kilo toneladas & 367600 & 274900 & 158600 \\
\hline RAEE por persona en kilos & 8,4 & 5,6 & 8,7 \\
\hline Ley & Sin Ley & 1672 & 20920 \\
\hline Ley aprobada & N.A. & 2013 & 2016 \\
\hline
\end{tabular}

\subsubsection{Marco Legal}

- Ley General de Residuos Sólidos 27314 y 27353 (20 de julio de 2000)

- Reglamento Nacional para la Gestión y Manejo de los Residuos de Aparatos Eléctricos y Electrónicos (27 de junio de 2012)

- Plan Nacional de acción ambiental 2011-2021

- Plan Nacional de Gestión Integral de Residuos Sólidos 2016-2024 


\subsubsection{Situación actual de la gestión de RAEE en Lima}

En algunos distritos de nuestra capital se vienen trabajando campañas de sensibilización a la ciudadanía con respecto al reciclaje de los RAEE.

Tabla $N^{\circ}$ 4. Situación actual de la gestión de RAEE en Lima

\begin{tabular}{|c|c|c|}
\hline Distrito & Iniciativa & Alianzas \\
\hline Lima Metropolitana & $\begin{array}{l}\text { - Gerencia de servicio a la ciudad y gestión ambiental } \\
\text { - } \quad \text { Campaña Tecnorecicla }\end{array}$ & MINAM \\
\hline Miraflores & $\begin{array}{ll}\text { - } & \text { Gerencia del medio ambiente } \\
\text { - } & 12 \text { contenedores de acopio de RAEE pequeños } \\
\text { - } & 2 \text { contenedores de RAEE medianos-grandes }\end{array}$ & $\begin{array}{l}\text { ASPAGER } \\
\text { Entel Perú }\end{array}$ \\
\hline La Molina & 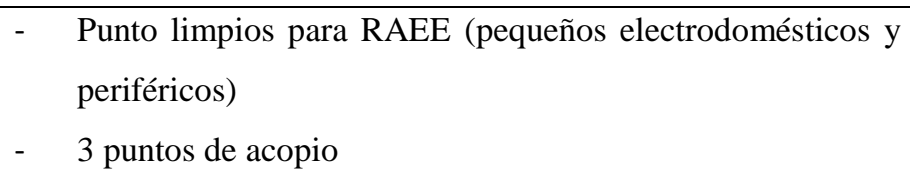 & ASPAGER \\
\hline Surco & $\begin{array}{ll}\text { - } & \text { Campañas de reciclaje } \\
\text { - } & \text { El reciclaje es obligatorio } \\
\text { - } & \text { Planta de reciclaje }\end{array}$ & MINAM \\
\hline San Miguel & - $\quad$ Donación del activo de la municipalidad & MINAM \\
\hline Villa el Salvador & $\begin{array}{ll}\text { - } & \text { Plan de manejo de residuos sólidos municipales } \\
\text { - } & \text { Ecoferia ambiental } \\
\text { - } & \text { Educaraee }\end{array}$ & MINAM \\
\hline
\end{tabular}

En la siguiente figura podremos conocer datos importantes acerca de las herramientas con las que cuenta Lima para afrontar el problema de los residuos sólidos. Increíblemente a pesar de que en estudios recientes se sitúa a nuestro país como unos de los productores en potencia de RAEE, llegando a cifras de 5 a 8 kilogramos por habitante al año, Lima con una población de aproximadamente 9 millones, solo cuenta con cuatro operadores de RAEE y dos rellenos de residuos peligrosos (ver Figura 4 y Anexo 3) 
Figura 4. Manejo de residuos sólidos en Lima Metropolitana: escenario actual

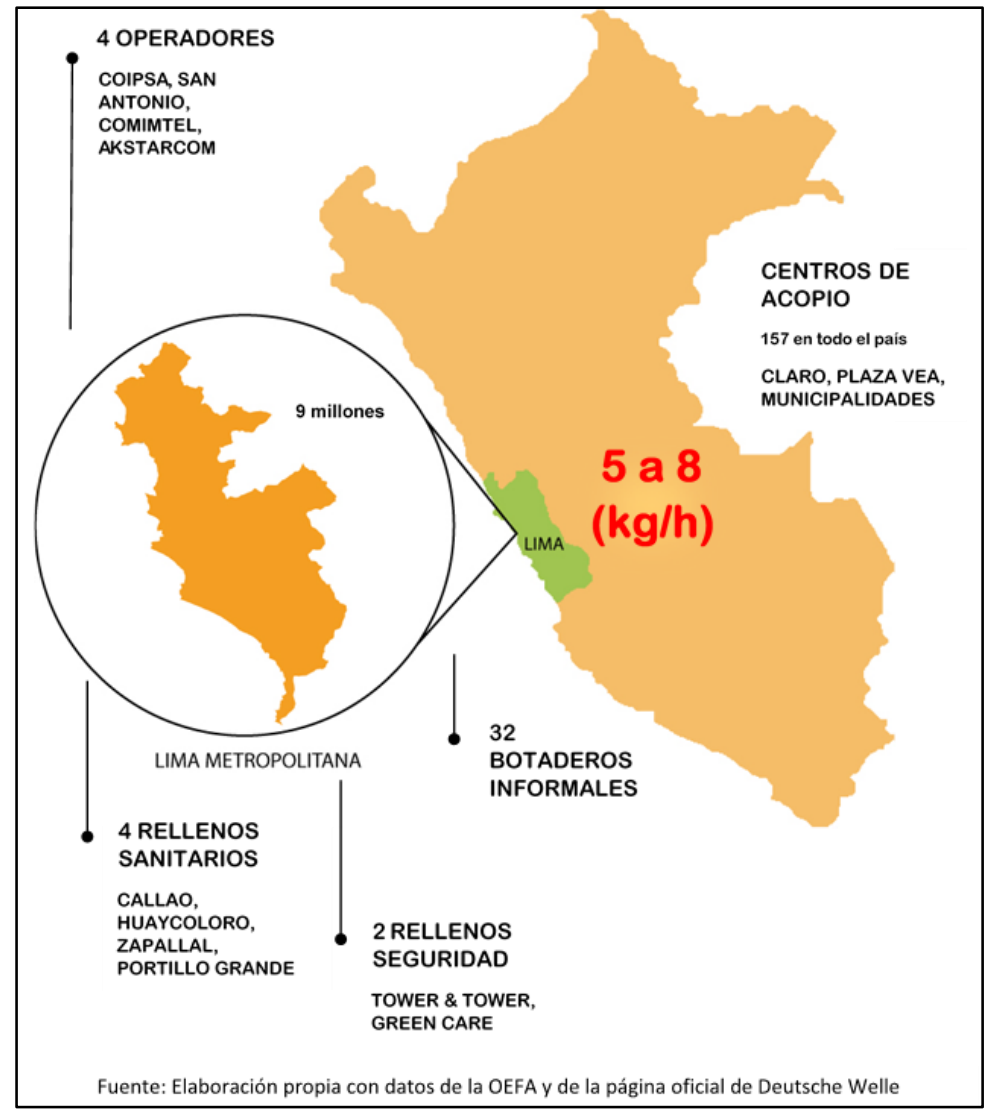

\subsubsection{Actores en la gestión de RAEE en Lima Metropolitana}

\subsubsection{Actores del Estado}

\subsubsection{Otros actores}

Trabajaremos empleando la debido a que nos permite analizar cómo ocurren los fenómenos dentro de su entorno real, considerando la información recolectada. Además, con ayuda de las herramientas que hemos elegido podremos establecer un vínculo directo con las unidades de análisis que participan en este proceso y así obtener información importante, dándole la validez respectiva al término de la investigación (Martínez, 2011).

Dado que nuestra investigación es cualitativa emplearemos el Método del Caso. Esta metodología nos permite generalizar teorías, encontrar nuevas evidencias, analizar las situaciones de un fenómeno, describir y ofrecer explicaciones e interpretaciones y explorar características de un fenómeno (Castro, 2010). 


\section{CAPÍTULO II. METODOLOGÍA DE LA INVESTIGACIÓN}

\subsection{Contexto}

\subsubsection{Segmento Especialistas (Profesionales expertos en el tema)}

Dos de las entrevistas fueron realizadas de manera presencial utilizando una grabadora de voz y la tercera por videollamada. La coordinación se realizó vía telefónica y por medio de correos electrónicos. El tiempo de las entrevistas se manejó en un rango de 10 a 45 minutos, ya que en este segmento la calidad de la información era de suma importancia para nuestra investigación.

La entrevista al operador de RAEE se realizó en las instalaciones de su planta, de esta manera pudimos presenciar cómo se desarrollaba el proceso de tratamiento de estos residuos. El ingeniero y catedrático nos recibió en una cafetería cerca de su centro de labores. Por último, el economista que entrevistamos accedió a la entrevista por videollamada desde su domicilio.

\subsubsection{Segmento Sector Privado y Estatal (Responsables de áreas relacionadas al tema)}

Seleccionamos a tres personas cuyos cargos, en el sector privado y estatal, corresponden al manejo de AEE. La información se obtuvo mediante el uso de cuestionarios que fueron enviados oportunamente a sus cuentas de correo electrónico, luego de gestionar la invitación por este mismo medio.

\subsubsection{Segmento Ciudadano (amas de casa)}

Las entrevistas fueron realizadas de manera presencial haciendo uso de una grabadora de voz. La coordinación se realizó de manera verbal minutos previos a la entrevista. El 
tiempo de las entrevistas se manejó en un rango de 1 a 15 minutos, dependiendo del conocimiento acerca del tema.

\subsubsection{Segmento Reciclador Informal}

Creímos conveniente incluir a un actor que no había sido mencionado en las entrevistas a los especialistas, pero sí en las entrevistas al segmento ciudadano. Estamos hablando del reciclador informal representado por un técnico que posea un taller en algún mercado concurrido. La entrevista fue realizada de manera presencial haciendo uso de una grabadora de voz. La coordinación se realizó de manera verbal minutos previos a la entrevista. El tiempo de la entrevista tuvo una duración de 4’02”.

\subsection{Herramientas para la investigación}

\subsubsection{Entrevista}

Es una herramienta flexible que tiene la particularidad de permitir el intercambio de información entre entrevistado y entrevistador. Las entrevistas fueron estructuradas ya que se siguió una guía de preguntas. Las preguntas del tipo opinión y conocimiento fueron incluidas para las entrevistas ya que nos interesaba conocer toda la información que puedan darnos nuestros colaboradores de acuerdo con su experiencia.

\subsubsection{Cuestionarios}

Ildefonso Grande (2005) la define como un conjunto articulado y coherente de preguntas redactadas en un documento para obtener la información necesaria para realizar la investigación. Pueden dirigirse a personas o empresas.

Durante el proceso de investigación, algunos de nuestros colaboradores no disponían de tiempo para atendernos. Por ello, nos vimos en la necesidad de enviarles los cuestionarios vía correo electrónico con el fin de no perder la oportunidad de contar con la información que nos podían brindar. 


\subsubsection{Observación}

De acuerdo a la definición que da Hernández Sampieri (2014), esta herramienta nos permite explorar y describir ambientes para comprender cómo se desarrollan las situaciones con el paso del tiempo.

Para nuestra investigación era importante conocer el paso a paso del segmento informal, así podríamos determinar mediante la observación del actor, datos importantes sobre la gestión o manejo del RAEE.

\subsection{Unidad de Análisis}

\subsubsection{Segmento Especialistas (Profesionales expertos en el tema)}

Seleccionamos a 3 personas expertas en el campo medioambientalista

1. Economista Manuel Arana

Especialista en Responsabilidad Social Corporativa

2. Ing. Ambiental Roxana Llerena

Jefa del Área de Ingeniería COMIMTEL

3. Ing. Químico Fernando Vásquez

Catedrático y Especialista en Temas Ambientales

\subsubsection{Segmento Sector Privado y Estatal (Responsables de áreas relacionadas al tema)}

1. Sr. Francisco Cabrera López

Encargado del Taller de Reparación Cobra Perú S.A. 
2. Ing. Luis Pachas

Encargado del Programa "Basura que no es Basura” de la Municipalidad de Miraflores

3. Sr. José Castro Manyari

Subgerente de Servicio Técnico de Importaciones Hiraoka

\subsubsection{Segmento Ciudadano (Amas de casa de seis distritos de la capital)}

Seleccionamos a cuatro amas de casa de los distritos de Lima Metropolitana, San Miguel, Surco, La Molina, Miraflores y Villa El Salvador, por ser las personas que administran sus hogares.

\subsubsection{Segmento Reciclador Informal}

Seleccionamos a un técnico que trabajara en un taller dedicado a la reparación de AEE y que se ubicara cerca o dentro de un mercado concurrido de la capital.

\subsubsection{Mapas conceptuales}

Haciendo uso de esta importante herramienta representaremos nuestra investigación en tres mapas conceptuales que resumen de manera didáctica el complejo sistema de reciclaje electrónico en Lima. 
Figura 5. Mapa conceptual 1: Actores que intervienen en la gestión de RAEE en Lima Metropolitana

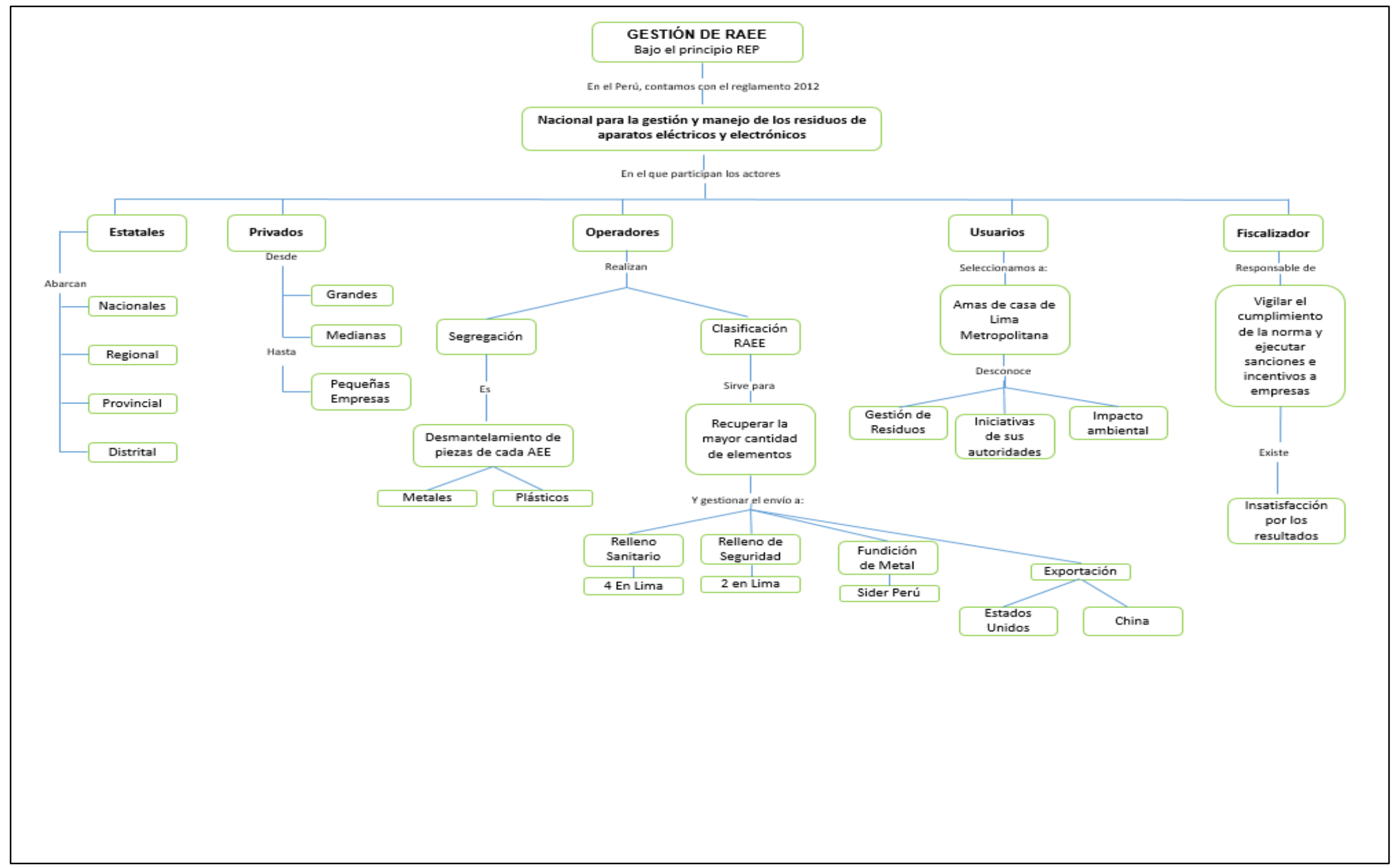


Figura 6. Mapa conceptual 2: Políticas del estado para la gestión de RAEE en Lima Metropolitana

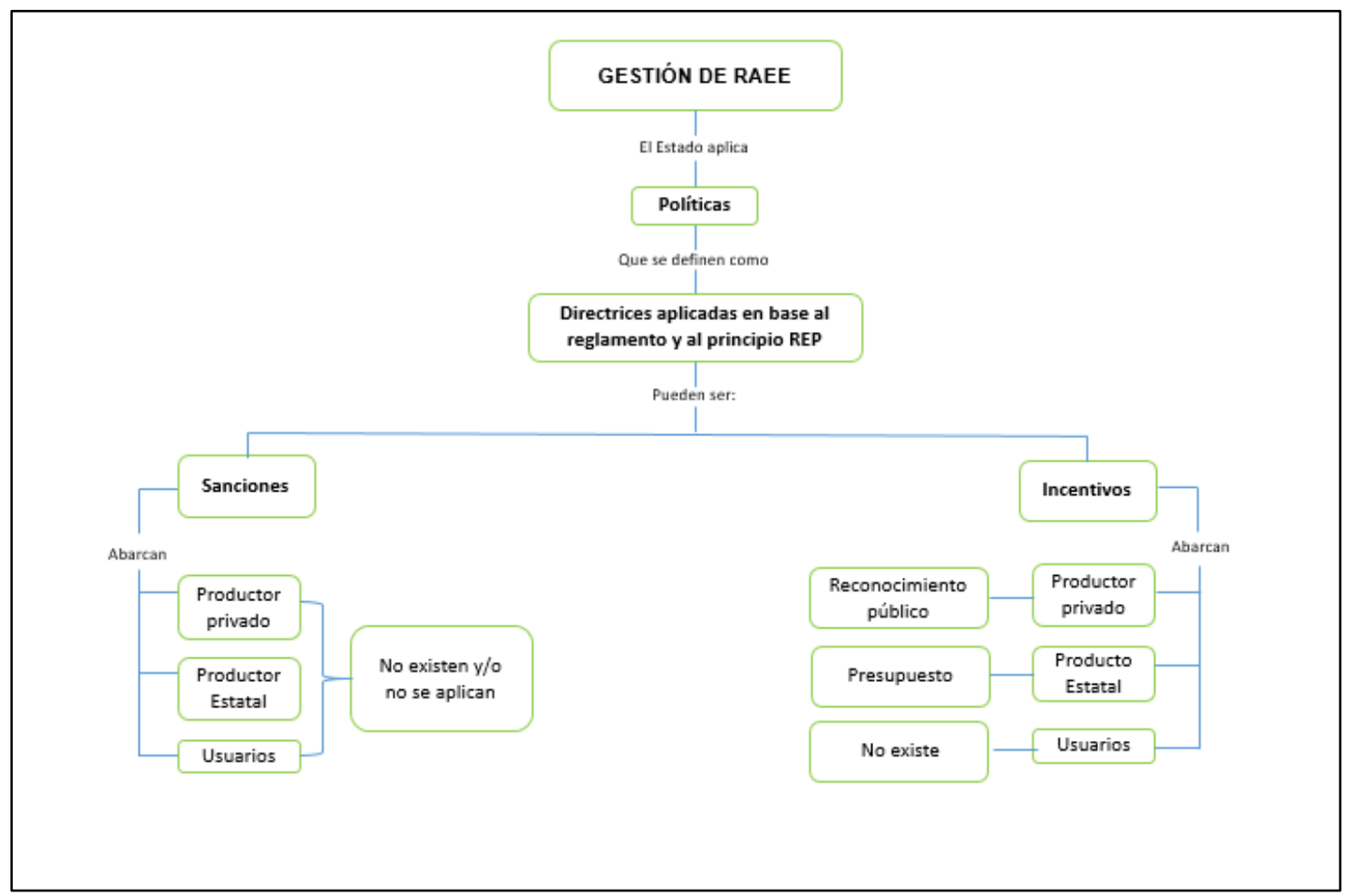

Figura 7. Mapa conceptual 3: Impacto negativo por una mala gestión de RAEE en Lima Metropolitana

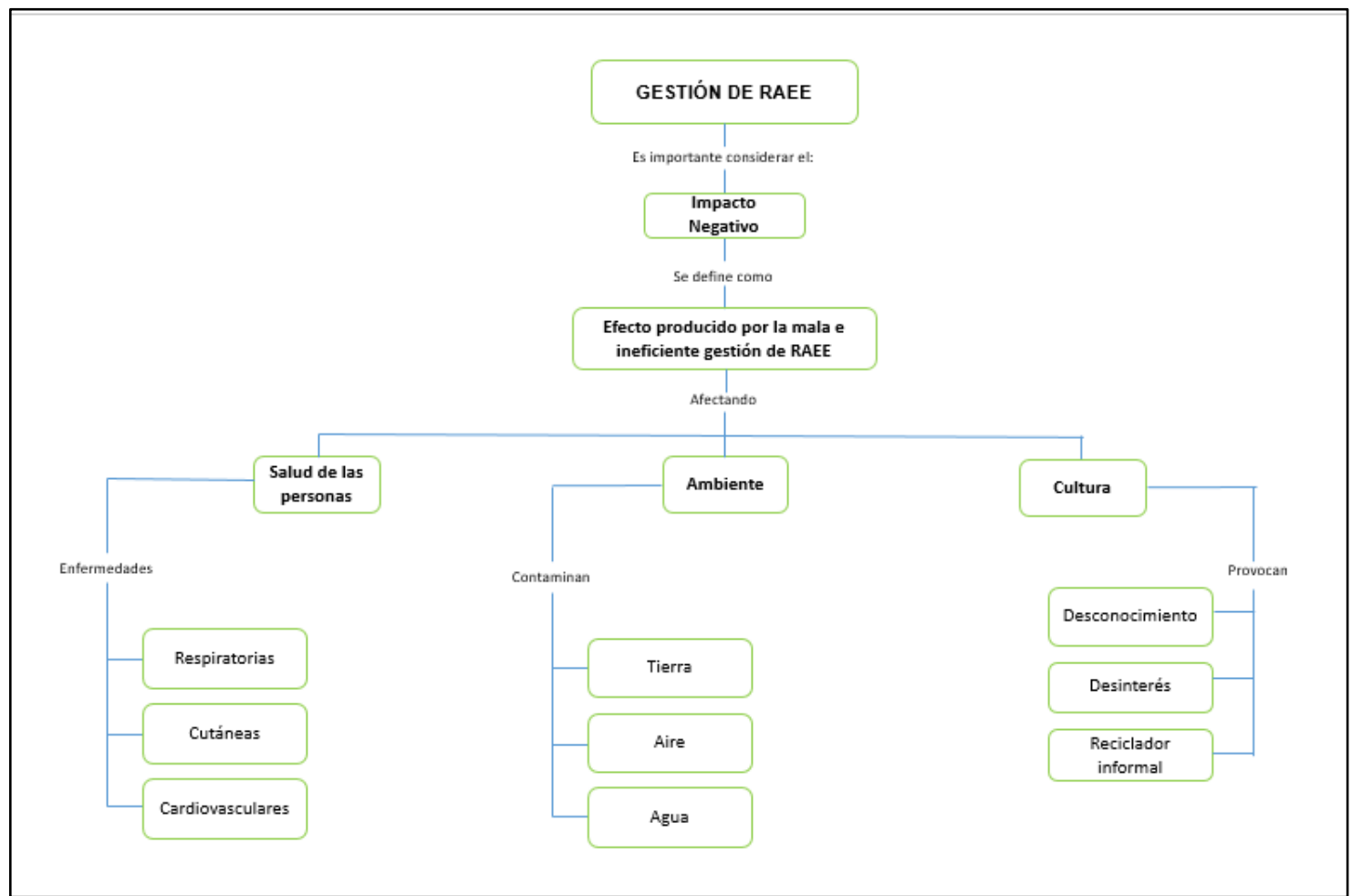




\subsection{Análisis de la investigación}

La técnica de la triangulación nos permite la contraposición de los tres métodos trabajados en nuestra investigación (Entrevista a profundidad, Cuestionario y Observación). En ese sentido, la información obtenida y que está centrada en el mismo problema, también ha podido ser contrastada a fin de recoger las impresiones de los diversos grupos con los que hemos trabajado.

\subsubsection{Objetivo 1}

Analizar las iniciativas y avances en el sistema de reciclaje electrónico por parte de los actores del sistema.

\section{- Estatal}

- Desde el 2013 el municipio de Miraflores impulsa el programa "Basura que no es basura" para recolectar grandes, medianos y pequeños electrodomésticos, además de celulares como una iniciativa, ya que no existe una obligación por ley.

- Actualmente tienen un convenio con entidades privadas y estatales con el fin recolectar RAEE y destinarlo a las plantas de tratamiento autorizadas (ENTEL Y ASPAGER).

- La municipalidad incluye como parte de su política interna la correcta aplicación del reglamento de residuos a pesar de manifestar que no existe una fiscalización por parte de la OEFA como organismo encargado.

- Privado

- Una de las iniciativas que promueve la empresa acerca de reciclaje electrónico es brindar capacitación a su personal sobre la gestión de RAEE

- Otra iniciativa está orientada al buen uso de los AEE que se utilizan dentro de la empresa, incluyendo aquellos que utilizados para el giro del negocio

- Transmitir información valiosa a los clientes con respecto al buen uso de los AEE también forma parte de una política de responsabilidad extendida del productor

- Cumple con los lineamientos establecidos por el Estado (Reglamento Nacional de Gestión de RAEE) para evitar alguna sanción posterior 
- Destina parte de su presupuesto para la recolección de RAEE

\section{- Especialistas}

- La creación del Ministerio del Ambiente y las normativas existentes sientan la base para una buena gestión de reciclaje electrónico

- Ambos expertos coincidieron en que el reciclaje que más se promueve es el orgánico, papel (incluyendo cartón) y tóner

- Las empresas que están más informadas con respecto al reciclaje electrónico pertenecen al giro de la informática y el reciclaje lo realizan más por un interés orientado a la actualización de los equipos con los que trabajan y no por el principio de REP

\section{- Operador}

- La mayor cantidad de RAEE recolectado corresponde a artículos informáticos, de telecomunicación y electrodomésticos

- Tiene como iniciativa la organización de ferias ambientales y de gestión de RAEE en colegios, empresas privadas y municipalidades. Dichas actividades se realizan en Lima y provincia

- Ciudadano

- Dentro de los actores que intervienen en la gestión de RAEE, este actor poco o nada conoce acerca de del tema

\subsubsection{Objetivo 2}

Evaluar los incentivos que el Estado ofrece y el nivel de satisfacción por parte de los beneficiados.

\section{- Estatal}


- Actualmente el Estado, a través del MINAM, asigna a las municipalidades un bono económico para que se realicen trabajos de concientización a la ciudadanía y así promover una cultura de reciclaje entre ella

- El MINAM brinda capacitación a las entidades del Estado acerca de la correcta gestión de RAEE

\section{- Privado}

- Las empresas valoran el reconocimiento público como único incentivo otorgado por el Estado a la gestión del reciclaje electrónico pues consideran que mejoran su imagen ante la sociedad

- El MINAM brinda capacitación a las entidades privadas acerca de la correcta gestión del reciclaje electrónico

\section{- Especialistas}

- Los incentivos no son suficientes y podrían proponerse descuentos tributarios para despertar mayor interés de las empresas con respecto al reciclaje electrónico

\section{- Ciudadano}

- Desde su papel como ciudadano, conoce acerca de la entrega de bolsas para otro tipo de reciclaje pero no para el electrónico

\subsubsection{Objetivo 3}

Identificar las políticas de fiscalización del Estado y si existen sanciones efectivas

\section{- Especialistas, Privado, Estatal, Operador}

- Las sanciones indicadas en el reglamento no son ejecutadas por el ente fiscalizador. No se tiene claro el panorama

- Existe un ente fiscalizador que es la OEFA, sin embargo, no cumple con el desarrollo de sus principales funciones: supervisar y ejecutar sanciones en las empresas que no cumplan con el reglamento vigente

- Existe un desconcierto ante la desproporción que puedan tener las sanciones 
- Los actores que intervienen en el proceso no asumen su responsabilidad, porque no son fiscalizados correctamente

\section{- Ciudadano}

- Desde su papel como ciudadano no conoce alguna sanción impuesta por sus autoridades que esté relacionada con el reciclaje. Sostiene que antes de sancionar se debería informar

\subsubsection{Objetivo 4}

Evaluar las consecuencias de la falta de reciclaje electrónico

\section{- Estatal}

- La falta de educación ambiental impide que los programas de reciclaje que impulsa el municipio tengan mayor convocatoria generando mayor acumulación de basura electrónica

\section{- Especialistas}

- La educación ambiental en la población es importante para realizar una buena gestión de reciclaje electrónico

- Algunos países envían sus desechos electrónicos a otros que no cuentan con un sistema eficiente de gestión de RAEE, en calidad de donación, ocasionando un exceso en la acumulación de RAEE

- Las sustancias que contiene un AEE son altamente peligrosas para la salud de las personas y del ambiente en general. La exposición de un RAEE en lugares inadecuados contamina el aire, agua y tierra (cadmio, plomo y mercurio)

\section{- Ciudadano}

- Considera que puede ser perjudicial para la salud pero no sabe en qué medida 


\section{CAPÍTULO III. CONCLUSIONES}

Como resultado de la investigación descriptiva que hemos realizado hemos podido identificar la información que nos ayudó a validar los cuatro objetivos que planteamos al inicio del presente trabajo. Asimismo, el Método del Caso nos permitió analizar el problema en su ámbito natural y a encontrar evidencias que finalmente nos permiten argumentar nuestra hipótesis.

\section{Objetivo 1}

Analizar las iniciativas y avances en el sistema de reciclaje electrónico por parte de los actores del sistema

En relación a los actores del Estado y de acuerdo a lo manifestado por los especialistas, el marco legal que existe actualmente en nuestro país para gestionar el reciclaje electrónico, propicia un escenario ideal para que se puedan impulsar iniciativas como la que desarrolla actualmente la Municipalidad de Miraflores con su programa denominado "Basura que no es basura", aunque dejan claro que no es suficiente si no existe una conciencia de reciclaje en la población. Asimismo, con respecto a los productores, la difusión de una cultura de prevención es considerada por la empresa privada como un factor importante para la conservación de los AEE a través de la capacitación al personal que trabaja directa o indirectamente en las áreas en las que se manipula RAEE. Del mismo modo, el operador está totalmente involucrado con la conservación del ambiente y promueve actividades que calen en la sociedad tanto en Lima como en provincias. Por otro lado, también se ha dejado en evidencia que el actor ciudadano no participa activamente debido a la poca información que ha recibido por parte de sus autoridades. El ciudadano manifestó su interés por conocer acerca del tema. 


\section{Objetivo 2}

Evaluar los incentivos que el Estado ofrece y el nivel de satisfacción por parte de los beneficiados

El actual Reglamento Nacional para la Gestión y Manejo de los RAEE ofrece un reconocimiento público a las empresas que cumplan con lo especificado por el Estado a través de su portal oficial. Sin embargo, los especialistas consideraron que el incentivo brindado es insuficiente. El descuento tributario fue la propuesta con mayor aceptación entre ellos. Consideraron que un beneficio directo por gestionar RAEE lograría mayor eficiencia de las empresas privadas en este tema, quienes actualmente cumplen con el fin de evitar multas. Inclusive el reciclaje electrónico podría ser parte de sus políticas internas.

Las empresas entrevistadas no han recibido reconocimiento alguno por parte del Estado pero creen que ayudaría a mejorar su imagen frente a sus clientes.

\section{Objetivo 3}

\section{Identificar las políticas de fiscalización del Estado y si existen sanciones efectivas}

Los especialistas indicaron que la fiscalización está representada en el Reglamento Nacional para la Gestión y Manejo de los RAEE por la OEFA. Los especialistas, operadores y productores entrevistados demostraron conocer acerca de ellas pero solo la Municipalidad de Miraflores recuerda haber recibido su visita pero no en calidad de inspección. Para los especialistas y operadores, el ente regulador es ineficiente en la gestión de fiscalización y ejecución de sanciones. La OEFA no realiza las visitas que el reglamento señala, ya que por el momento enfoca sus acciones o gestiones en el sector minero. 


\section{Objetivo 4}

\section{Evaluar las consecuencias de la falta de reciclaje electrónico}

De los actores entrevistados, los especialistas, productores y operadores manifestaron en su totalidad el conocimiento de las consecuencias negativas que la mala gestión de RAEE ocasiona al ambiente y a la salud de las personas. Ellos resaltaron que una incorrecta manipulación y exposición de los RAEE es altamente peligroso para la salud, ya que estos contienen minerales peligrosos como el cadmio, plomo y mercurio. Los especialistas y operadores coincidieron en que el reciclador informal es un personaje que sobrevive debido a que las personas lo utilizan como medio para desechar sus desperdicios electrónicos, entre otros. En ese sentido, el reciclador informal solo busca el beneficio económico y no tiene conciencia de la contaminación que produce ni de las medidas de seguridad con las que debe contar cuando manipula RAEE. Por otro lado, los ciudadanos entrevistados indicaron que seguro existen consecuencias, pero no precisaron la magnitud del impacto que este pueda ocasionar.

\section{Hipótesis}

La falta de una cultura de reciclaje entre los actores que intervienen en el manejo de un RAEE eficiente, pone en riesgo la sostenibilidad del sistema

Las deficiencias encontradas en el rol que cumplen los actores dentro de la gestión eficiente de un RAEE nos permiten identificar lo siguiente:

- El ciudadano como uno de los principales actores del proceso desconoce la forma correcta de reciclar un AEE cuando este llega al final de su vida útil

- El ciudadano no recibe información por parte de sus autoridades ni tiene la iniciativa para buscarla, a pesar de generar RAEE

- El sector privado como productor de RAEE centra sus esfuerzos en el cumplimiento del reglamento establecido por el Estado, a fin de evitar sanciones. Al tenerlo como una obligación, no impulsa entre sus colaboradores una cultura de reciclaje electrónico

- El Estado solo establece metas de recolección de RAEE al sector privado 
- El operador manifiesta que a las empresas se les complica cumplir con las metas de recolección de RAEE establecidas por el Estado, por ser desproporcionadas

- El operador realiza actividades enfocadas en impulsar la cultura de reciclaje de AEE como ferias y visitas a empresas o centros educativos. Sin embargo, es insuficiente ya que es necesario el apoyo del Estado

- Los especialistas coinciden en que son pocas las empresas que conocen acerca del reciclaje electrónico. El interés por desechar RAEE deviene de un interés propios del giro de su negocio o por el cumplimiento de las normativas dadas por el Estado

Por lo expuesto, podemos concluir:

Los productores cumplen con la normativa para evitar las sanciones por parte del Estado y no por tener un compromiso directo con la gestión eficiente del RAEE. Asimismo, los incentivos no son suficientes para instaurar una política de gestión permanente en sus empresas. Esto explica la poca o nula cultura de reciclaje en el actor. Los ciudadanos, actores importantes en este sistema, no reciclan el RAEE porque, al no conocer la importancia para el cuidado del medio ambiente, lo desechan con los demás residuos orgánicos o los almacenan indefinidamente en sus casas pensando que servirán en algún momento. El desconocimiento del manejo de RAEE por parte del ciudadano asegura la permanencia del reciclador informal al considerar que obtendrá un mayor beneficio vendiendo lo que ya no utiliza. Esto, sin considerar que estos aparatos no tendrán al fina el correcto manejo de reciclaje.

El operador manifestó enfáticamente la falta de apoyo del Estado en la gestión de reciclaje electrónico, ya que no recibe ni orientación ni el soporte necesario para las gestiones burocráticas que el proceso requiere.

El Estado no fiscaliza a las empresas que participan de la gestión de RAEE, ya que mencionan que actualmente sus esfuerzos se encuentran direccionados en el sector minero.

Asimismo, no dimensiona correctamente y planifica metas desproporcionadas para las empresas participantes del sistema. 
En tal sentido, podemos validar nuestra hipótesis bajo el supuesto de que la falta de interés limita una correcta gestión de reciclaje electrónico y no impulsa el desarrollo de la cultura de reciclaje electrónico entre todos los actores del sistema.

\section{Limitaciones}

Durante el desarrollo de nuestra investigación se presentaron diferentes situaciones que nos impidieron recolectar mayor información.

- El primer inconveniente se presentó en la búsqueda de fuentes bibliográficas ya que nuestro tema es considerado nuevo para el mercado nacional

- Para el trabajo de campo buscamos la posibilidad de contactar con el Ministerio del Ambiente, principal gestor del tema en estudio, pero a pesar de enviar correos electrónicos, no recibimos respuesta

- Con respecto al ente fiscalizador (OEFA) y dada la importancia del rol que juega en el sistema, enviamos un correo electrónico para solicitar una cita y la respuesta fue negativa, ya que indican que no brindan citas o entrevistas

- La entrevista con al menos un reciclador informal era fundamental para nuestro trabajo pero por motivos de tiempo fue imposible

- Lograr concertar entrevistas con al menos 2 municipalidades más, nos hubiera ayudado a ampliar aún más el concepto que trabajan las autoridades locales referente al tema de reciclaje electrónico

- A pesar de haber conseguido una cita para entrevistar a un representante del MINSA, el cambio de gobierno impidió la misma 


\section{Aprendizaje}

\section{Aprendizaje del Tema}

Gracias a la investigación que durante 6 meses hemos realizado, pudimos conocer información relevante que nos ha permitido entender cómo funciona el sistema y como se aplica eficientemente la gestión de RAEE. Dentro de los puntos más resaltantes hemos conocido las características, la clasificación de los residuos en sus diez categorías, las consecuencias para el medio ambiente y la salud. Asimismo, encontramos los antecedentes de las antiguas gestiones de RAEE en el mundo. Esta investigación nos ha permitido conocer las estadísticas y cifras más importantes a nivel mundial en lo que al RAEE respecta. Yendo más a detalle y enfocados a nuestra investigación, hemos podido conocer la gestión de RAEE en Lima Metropolitana, así como el marco legal que incluye el vigente reglamento nacional para la gestión y manejo de los residuos de aparatos eléctricos y electrónicos. El mismo fue instaurado con la gestión del ministro Manuel Pulgar Vidal. Gracias a esta investigación hemos conocido a los actores involucrados en todo el proceso que cuentan con derechos y obligaciones para la adecuada gestión de los RAEE en las diferentes etapas de manejo.

\section{Aprendizaje de los investigadores}

Conocer acerca del reciclaje eficiente de los RAEE ha sido bastante enriquecedor y nos ha permitido entender que el correcto manejo de estos residuos al llegar al final de su vida útil permite una mejor preservación del medio ambiente, influyendo directamente en la reducción de contaminación y enfermedades para la salud del ser humano.

El trabajo de campo ha sido arduo, pero con resultados muy favorables. Hemos realizado entrevistas a todos los actores del sistema, incluyendo una visita a la planta recicladora especializada en RAEE. Además, hemos podido conocer de primera mano lo que el reglamento nacional estipula para cada uno de los actores. Ellos nos han mencionado las oportunidades de mejora que demandan directamente al Estado. Hemos aprendido y validado que en el Perú la falta de cultura de reciclaje de RAEE dificulta la concientización de los actores del sistema, las acciones que se están realizando son importantes pero mínimas en comparación a lo que Lima demanda. Por ejemplo, sabemos 
que aún tenemos pocos rellenos sanitarios y la expansión de estos permitirá gestionar mejor el RAEE que generamos en nuestra ciudad. Cada día se suman más empresas privadas a esta gran iniciativa. Sin embargo, el ciudadano de a pie o ama de casa aún desconoce el tema. Es importante que sus autoridades puedan brindar más información e impulsar el reciclaje electrónico mediante incentivos que los beneficien directamente al reciclar sus RAEE. La investigación nos ha permitido además, aplicar nuevas metodologías y herramientas para nuestra tesis.

\section{Hallazgos}

- El estado no aplica el principio de REP en el mercado comercial

- El Estado no fija metas para el Sector Estatal, solo incluye al Sector Privado

- El Estado no sanciona en caso las metas impuestas no se lleguen a cumplir

- El operador de RAEE asume todos los costos por el tratamiento de una RAEE

- La permanencia de los operadores está en riesgo en tanto el Estado no apoye su papel dentro del sistema

- Existe un déficit de profesionales especializados en el tema de RAEE

- Al término de las entrevistas logramos despertar el interés de las amas de casa que deseaban conocer más acerca del tema

- Hay muy poca información acerca de nuestro tema de investigación y por ende las estadísticas son limitadas

- El Sector Informal representa un riesgo a futuro en el desarrollo de la gestión eficiente de los RAEE 


\section{Recomendaciones}

- Estado

- En algunos países europeos, el productor incluye un costo por reciclaje del producto que comercializa. De esta manera permite que el ciclo no se cierre al concretar la venta sino incluye la posventa como parte de su responsabilidad

- Es importante impartir los conocimientos necesarios acerca del reciclaje desde muy temprana edad. Por ello, debe ser prioridad para las autoridades incluir este tema dentro de la currícula estudiantil

- Fortalecer el trabajo articulado entre todos los actores que participan del sistema. La coordinación entre los ministerios del Estado es fundamental

- Buscar alianzas con los medios de comunicación para la difusión del tema

- El sector público debe estar incluido dentro del sistema cuando nos referimos a la asignación de metas

- Durante la entrevista al operador de RAEE pudimos notar la ausencia del Estado en los pasos que debe seguir el operador cuando gestiona RAEE. En ese sentido, este aspecto debe reevaluarse si queremos garantizar la existencia de un actor que cumple un rol muy importante dentro del sistema

- La plataforma SIGERSOL, creada desde el 2008 y utilizada para reportar el avance de la gestión de residuos sólidos de las municipalidades, debe contemplar dentro de sus clasificaciones a los RAEE y el registro en este sistema no debe ser una vez al año sino en forma periódica. Asimismo, debe difundirse el uso de esta plataforma entre la ciudadanía ya que fue uno de los objetivos de la creación del sistema

- Estudiantes

- Para las próximas investigaciones sería importante considerar ampliar el tamaño de la muestra ampliándola a más distritos de la ciudad de Lima y provincias

- Sería muy enriquecedor visitar los diferentes ministerios del Estado para establecer el nivel de alineamiento en lo que a gestión de RAEE se refiere 
- Estudiar e identificar los procesos que puedan requerir una mejora con el fin de agilizar y mejorar. Facilitar el trabajo de actores como el operador es importante para asegurar su permanencia en el sistema

- Investigar, de la mano de especialistas, casos específicos en el sector salud

- Investigar los niveles permitidos de las sustancias que contiene un RAEE en el agua, suelo y aire

- Investigar a detalle la gestión de RAEE en países que hayan obtenido resultados sobresalientes dentro de su sistema

- Hacer un estudio direccionado a como el tratamiento de los RAEE podría representar un riesgo si cayera en manos del sector informal en nuestro país 


\section{REFERENCIAS BIBLIOGRÁFICAS}

ALAYZA, C., CORTÉS, G., HURTADO, G., MORY, E., \& TARNAWIECKI, N. (2012). Iniciarse en la Investigación Académica. Lima, Perú: Universidad Peruana de Ciencias Aplicadas S.A.C.

BUENOS AIRES CIUDAD. (s.f.). Residuos de Aparatos Eléctricos y Electrónicos (RAEE). Recuperado de http://www.buenosaires.gob.ar/agenciaambiental/residuos-deaparatos-electricos-y-electronicos

Castro, E. (2010). El estudio de casos como metodología de investigación y su importancia en la dirección y administración de empresas. Revista Nacional de $\begin{array}{llll}\text { Administración. } & 1 & \text { (2).31-54. } & \text { Recuperado }\end{array}$ de https://dialnet.unirioja.es/descarga/articulo/3693387.pdf [Consultado el 10 de abril de 2018]

CEPIS. (2000). Prevención de la Contaminación en la Pequeña y Mediana Industria. Lima, Perú.

CONAM (2000). ¿Nos importa el Medio Ambiente? Encuesta de Percepción Ciudadana de los Problemas Ambientales de Lima y Callao. Lima, Perú.

CONVENIO DE BASILEA. (1992). Recuperado de http://www.basel.int/Portals/4/Basel\%20Convention/docs/text/BaselConventionTexts.pdf

DIARIO OFICIAL. (2016). Establece marco para la gestión de residuos, la responsabilidad extendida del productor y fomento al reciclaje. Recuperado de http://portal.mma.gob.cl/wp-content/uploads/2015/06/do-20160601-web.pdf 
ECONOMÍA CIRCULAR Y MINERÍA URBANA. (2013). Informe sobre la Industria de Gestión de RAEE de Argentina. Recuperado de https://mineriaurbana.org/2013/06/04/informe-sobre-la-industria-de-gestion-de-raee-deargentina

ECOPORTAL. (2005). Basura cero: una alternativa sustentable. Recuperado de https://www.ecoportal.net/temas-especiales/basuraresiduos/basura_cero_una_alternativa_sustentable

EL COMERCIO. (2014). ¿Cuál es el manejo de la basura electrónica en el Perú? Recuperado de https://elcomercio.pe/economia/peru/manejo-basura-electronica-peru$\underline{172889}$

EL COMERCIO. (2014). Perú produce 20 mil toneladas de residuos electrónicos al año. Recuperado de https://elcomercio.pe/lima/peru-produce-20-mil-toneladas-residuos$\underline{\text { electronicos-ano-311292 }}$

GARCÍA, B. (2016). Basura Electrónica: Un mundo dividido. Madrid, España: Pigmalión.

GRANDE, I., \& ABASCAL, E. (2005). Análisis de Encuestas. Madrid, España: ESIC. GSMA. (2015). eWaste en América Latina: Análisis estadístico y recomendaciones de política pública. Recuperado de https://www.gsma.com/latinamerica/es/ewaste-2015

HERNÁNDEZ, R., FERNÁNDEZ, C., BAPTISTA, Ma. (2014). Metodología de la Investigación. Ciudad de México, México: Mc Graw Hill Education.

LA REPÚBLICA. (2012). Mucho cuidado con la basura electrónica. Recuperado de http://larepublica.pe/archivo/680047-mucho-cuidado-con-la-basura-electronica Martínez Ruíz, H. (2014). Metodología de la Investigación (Sexto semestre). México D.F.: Cengage Learning 
MINAM. (2016). Aprende a Prevenir los Efectos del Mercurio. Lima.

OROZCO BARRENETXA, C., PÉREZ SERRANO, A., NEVES GONZÁLES DELGADO, M., RODRÍGUEZ VIDAL, F., \& ALFAYATE BLANCO, J. (2011). Contaminación Ambiental: Una visión desde la química. Madrid, España: Ediciones Paraninfo.

RAEE. (s.f.). Recuperado de http://www.raee-peru.pe

REGLAMENTO NACIONAL PARA LA GESTIÓN Y MANEJO DE LOS RESIDUOS DE APARATOS ELÉCTRICOS Y ELECTRÓNICOS (2012). Recuperado de http://www.raee-peru.pe

RESIDUOS PROFESIONAL. (2018). Publicado un informe sobre tendencias de los RAEE a nivel mundial. Recuperado de https://www.residuosprofesional.com/informetendencias-raee-nivel-mundial/

SÁNCHEZ RODRÍGUEZ, R., \& BONILLA, A. (2005). Urbanización, Cambios Globales en el Ambiente y Desarrollo Sustentable en América Latina. Sao Paulo, Brasil: IAI, INE, UNEP.

SILVA, U. (2009). Gestión de Residuos Electrónicos en América Latina. Santiago, Chile: Ediciones Sur.

TELAM. (2016). Argentina ingresará en el millonario negocio de los residuos electrónicos. Recuperado de http://www.telam.com.ar/notas/201606/151069-argentinaexportacion-residuos-electronicos-grupo-pelco.html. 


\section{ANEXOS}

$\underline{\text { Anexo } 1}$

El mundo generará 54 millones de toneladas de chatarra electrónica en el 2025

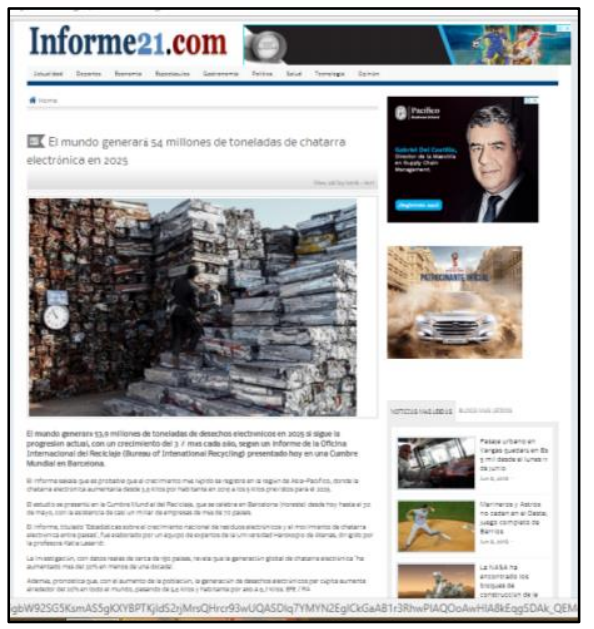

https://informe21.com/ciencia-y-tecnologia/el-mundo-generara-54-millones-detoneladas-de-chatarra-electronica-en-2025

\section{$\underline{\text { Anexo 2 }}$}

Ministerio del Ambiente: hay un déficit de 246 rellenos sanitarios

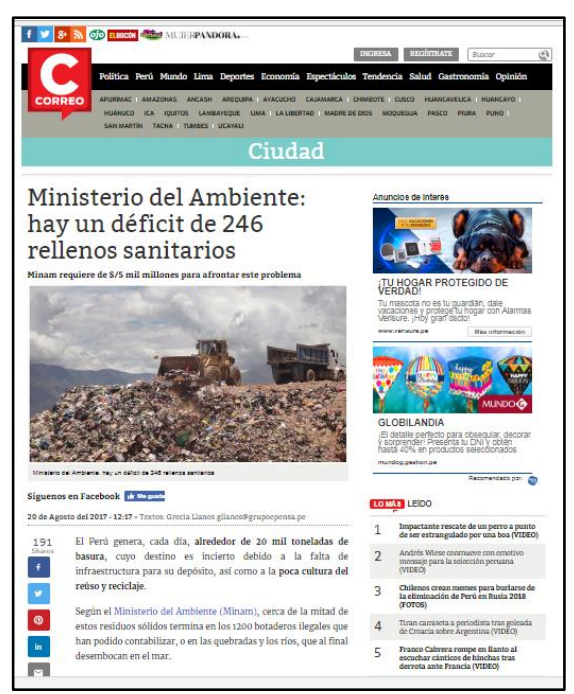

https://diariocorreo.pe/ciudad/ministerio-del-ambiente-hay-un-deficit-de-246-rellenossanitarios-768692/ 
$\underline{\text { Anexo } 3}$

\section{El inexplotado potencial del reciclaje en Latinoamérica}

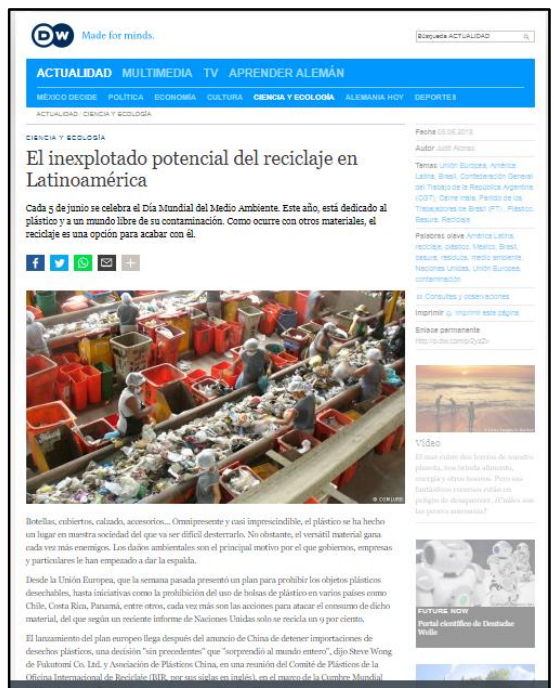

http://www.dw.com/es/el-inexplotado-potencial-del-reciclaje-enlatinoam\%C3\%A9rica/a-44089063 


\section{Anexo 4}

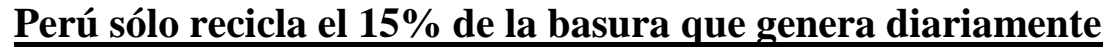

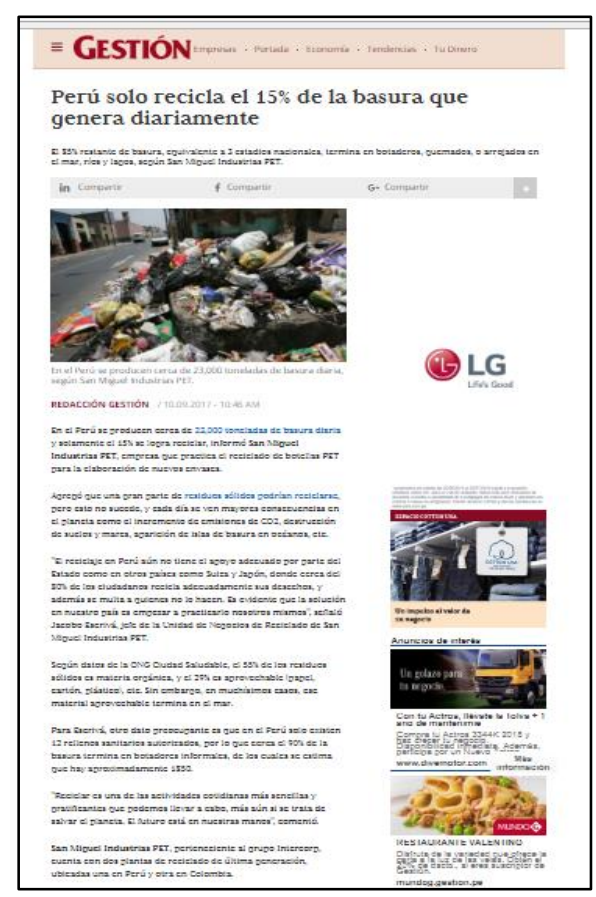

https://gestion.pe/economia/empresas/peru-recicla-15-basura-genera-diariamente143243 
$\underline{\text { Anexo } 5}$

Sepa dónde dejar sus celulares y televisores antiguos para no contaminar el ambiente

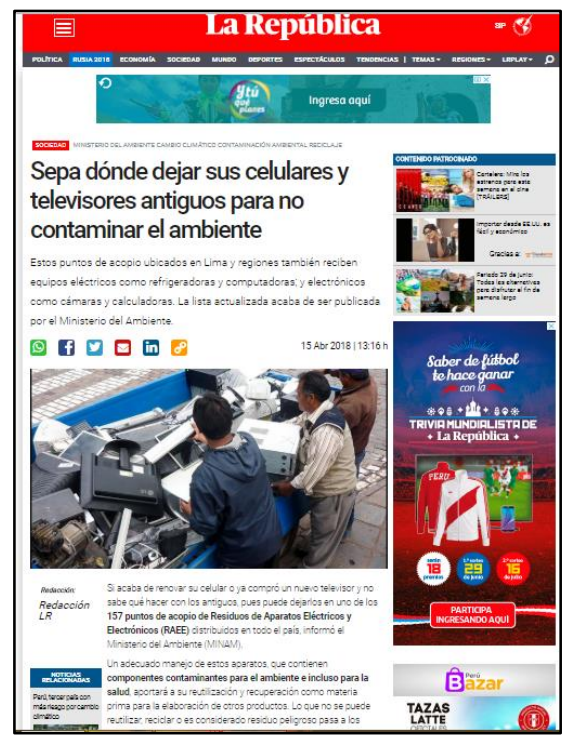

https://larepublica.pe/sociedad/1227476-sepa-donde-dejar-sus-celulares-y-televisoresantiguos-para-no-contaminar-el-ambiente 